\title{
Polimorfismos em Genes Relacionados ao Sistema Renina-Angiotensina-Aldosterona, Associação Com a Doença Arterial Coronariana e suas Características Anatômicas
}

\author{
Francisco Antonio Helfenstein Fonseca, Maria Cristina de Oliveira Izar \\ São Paulo, SP
}

A ativação do sistema renina-angiotensina-aldosterona (RAAS) constitui-se num fator de risco para eventos cardiovasculares. A angiotensina II age nos receptores AT1 e AT2. A estimulação dos receptores AT1 está associada à disfunção endotelial, principalmente, como conseqüência de um aumento na produção de espécies reativas de oxigênio, vasoconstrição, ativação plaquetária, maior liberação do fator inibidor da ativação do plasminogênio tipo 1 (PAI-1), além da ativação de certos genes, ditos immediate early genes, tais como o c-fos, c-jun, da hipertrofia miocárdica, formação de tecido conectivo, síntese de endotelina, e ativação de fatores de crescimento, como o PDGF(fator de crescimento derivado das plaquetas) e o TGF-beta 1 (fator de crescimento transformador - beta 1). Já a estimulação dos receptores AT2 pode atenuar os efeitos proliferativos da estimulação dos receptores AT1. A contribuição desses efeitos tem sido estudada, com relação ao desenvolvimento e progressão da aterosclerose, na reestenose após a angioplastia e no remodelamento ventricular na insuficiência cardíaca ${ }^{1}$. Também os efeitos do bloqueio dos receptores AT1 da angiotensina II têm sido alvo de grande investigação.

No campo da genética, o estudo de polimorfismos em genes relacionados ao sistema renina-angiotensina-aldosterona (SRAA) vem merecendo uma avaliação mais criteriosa, já que os resultados de diversas pesquisas têm sido díspares em apontar uma associação clara entre o risco de doença arterial coronariana, infarto do miocárdio, reestenose pós-angioplastia, ou mesmo de hipertrofia ventricular, com a presença desses polimorfismos genéticos. Os genes da ECA, do angiotensinogênio, do receptor tipo 1 da angiotensina II, e da aldosterona sintetase são os mais debatidos.

Os níveis plasmáticos da enzima conversora da angiotensina (ECA) em humanos estão relacionados ao polimorfismo inserção (I) / deleção (D) no gene da ECA, situado no cromossomo 17: a deleção de uma seqüência de pares de base no intron 16 do gene da ECA está associada com maiores níveis de transcrição do RNA mensageiro e, conseqüentemente, com maior expressão da ECA.

Setor de Lípides, Aterosclerose e Biologia Vascular da Universidade Federal de São Paulo

Endereço para correspondência: Francisco A. H. Fonseca, Cardiologia, Setor de Lípides, Aterosclerose e Biologia Vascular - UNFESP

Rua: Pedro de Toledo, 458 - Cep 04039-001 - São Paulo - SP

E-mail: lipides@superig.com.br
Assim, os portadores do genótipo DD têm níveis de ECA maiores do que os portadores dos genótipos ID ou II. Estudos recentes sugerem que o genótipo DD da ECA associa-se a um maior risco de doença arterial coronariana. Na cardiologia intervencionista, observou-se forte associação desse polimorfismo na reestenose após implante de stent, sem associação com a angioplastia convencional, o que pode ser explicado pelo fato de que a contribuição da hiperplasia neointimal para a reestenose é muito mais importante após o implante do stent do que na angioplastia com cateter balão. Também parece participar na regulação do tônus vasomotor, sendo descrita associação com vasoespasmo, além de menores taxas de patência na artéria relacionada ao infarto e maior risco de oclusão total do segmento dilatado 6 meses após angioplastia bem sucedida. Estes dados sugerem uma interação multifatorial do polimorfismo I/D da ECA na doença arterial coronariana. Possíveis mecanismos incluem interações com a formação neointimal, espasmo coronariano e trombose coronariana².

0 gene que regula o angiotensinogênio, situado no cromossomo 1q42 relaciona-se à doença arterial coronariana, hipertensão e à recorrência de reestenose após angioplastia. Dois polimorfismos foram estudados: o M235T e o T174M, que não contribuiram para o risco de doença arterial coronariana ou hipertensão arterial ${ }^{3}$, embora o primeiro em homozigose tenha se associado à prevenção da reestenose após angioplastia, quando tratado com quinapril ${ }^{4}$. Em outro estudo, entretanto, o alelo T235 foi considerado preditor independente de doença arterial coronariana, com um risco duas vezes maior, sem efeitos do polimorfismo I/D do gene da ECA 5 .

A variante $A 1166 C$ no gene que codifica o receptor tipo 1 da angiotensina II, situado no cromossomo 3 , correlaciona-se à hipertensão arterial $^{6}$, provavelmente por uma interação epistática com o polimorfismo I/D do gene da ECA e, possivelmente, associe-se também à doença arterial coronariana7,8.

Nesta edição dos Arquivos Brasileiros de Cardiologia, Araújo, e cols. avaliaram a prevalência da variante A1166C do gene AT1R em estudo caso e controle que incluiu uma amostra de 110 pacientes com infarto do miocárdio e 104 controles. Os critérios de inclusão foram a presença de aterosclerose coronariana caracterizada como lesão > 50\%, sendo avaliados ainda a extensão da doença (pelo número de vasos acometidos por aterosclerose), a morfologia da placa aterosclerótica e o escore de risco coronariano. Os autores não encontraram associação entre o polimorfismo em estudo e a doença arterial coronariana, bem como com a sua 
extensão, com as características da placa aterosclerótica ou com o escore de risco coronariano. A literatura tem mostrado que 0 estudo de polimorfismos genéticos na predição do risco em doenças complexas, multifatoriais pode ser um grande desafio. Uma única substituição de nucleotídeo em um gene candidato pode ser insu- ficiente para demonstrar seu efeito em termos individuais. Entretanto, quando este mesmo polimorfismo apresentar uma freqüência populacional considerável, seu impacto poderá ser mais relevante. A análise conjunta de múltiplos marcadores genéticos parece ser uma abordagem mais promissora.

\section{Referências}

1. Dietz R, von Harsdorf R, Gross M, et al. Angiotensin II and coronary artery disease, congestive heart failure, and sudden cardiac death. Basic Res Cardiol. 1998; 93(Suppl 2):101-8.

2. Bauters $C$, Amouyel P. Association between the ACE genotype and coronary artery disease. Insights from studies on restenosis, vasomotion and thrombosis. Eur Heart J. 1998;19 (SupplJ):J24-9.

3. Nair KG, Shalia KK, Ashavaid TF, Dalal JJ. Coronary heart disease, hypertension, and angiotensinogen gene variants in Indian population. J Clin Lab Anal. 2003;17:141-6.

4. Toyofyuku M, Imazu M, Sumii K, et al. Influence of angiotensinogen M253T gene polymorphism and an angiotensin converting enzyme inhibitor on restenosis after percutaneous coronary intervention. Atherosclerosis. 2002; 160: 339-44.
5. Katsuya T, Koike G, Yee TW, at al. Association of angiotensinogen gene T235 variant with increased risk of coronary heart disease. Lancet.1995;345:1600-3.

6. Pirola CJ. Molecular genetics of essential hypertension. Susceptibility and resistance genes. Medicina. 2000;60:59-66

7. Tiret L, Bonnadeaux A, Poirier O, et al. Synergistic effects of angiotensin-converting enzyme and angiotensin-II type receptor gene polymorphism on risk of myocardial infarction. Lancet. 1994;344:910-4.

8. Wang JG, Staessen JÁ. Genetic polymorphisms in the renin-angiotensin system: relevance for susceptibility to cardiovascular disease. Eur J Pharmacol. 2000;410:289-302. 